\title{
A Case Report On Congestive Cardiac Failure Due To Hyperthyroidism
}

\author{
BA Yakasai* and HB Yakasai \\ Kaduna State University, Nigeria
}

Received: November 13, 2017; Accepted: December 4, 2017 ; Published: January 1, 2018

*Corresponding author: BA Yakasai, Kaduna State University, Nigeria, E-mail: bashiryaks@yahoo.com

\begin{abstract}
A 51-year-old married woman referred to Nigerian Air Force hospital Kaduna from a local hospital in Kebbi, Kebbi State, Nigeria because of persistent epigastric pain that lasted several weeks. The pain was resistant to any anti acids or proton pump inhibitors. In addition, she complained of hand shaking, feeling excessive bodily heat, breathlessness on exertion, recurrent diarrhoea and loss of weight despite having a very good appetite.
\end{abstract}

On arrival, the patient was comfortable and in no acute distress. Her vital signs other than the rapid irregularly pulse rate, were within normal limits. Her Jugular venous pulsation was slightly elevated, and her carotid upstroke was normal, and no carotid bruits were appreciated. However, a symmetrically enlarged, nontender thyroid gland was palpable, with a bruit over the left lobe. Mild stare and lid lag were noticed, along with mild tremor of the outstretched hands. Chest examination revealed no abnormalities. The abdomen was mildly tender, and the liver palpable $2 \mathrm{~cm}$ below the costal margin. A slight pitting ankle oedema was noted bilaterally.

The results of routing laboratory investigations were unremarkable except for the abnormal thyroid function tests (TFT's) which was consistent with hyperthyroidism. The ECG revealed atrial fibrillation with a left ventricular hypertrophy. An initial diagnosis of atrial fibrillation and congestive heart failure (CHF) secondary to thyrotoxicosis was made. The patient was placed on intravenous furosemide, oral digoxin and angiotensin-converting enzyme (ACE) inhibitors. She was also placed on carbimazole $20 \mathrm{mg}$ daily and atenolol $100 \mathrm{mg}$ daily. Within the next 5 days her ECG spontaneously converted to sinus rhythm, and her TFTs markedly improved.

Key Words: Atrial Fibrillation; Congestive Cardiac Failure; Sinus Rhythm; Furosimide; Carbimazole;

\section{Introduction}

Hyperthyroidism imposes a severe strain on the cardiovascular system, which expresses itself in the clinical feature referred as thyroid cardiac disease. This is diagnosed when atrial fibrillation and congestive cardiac failure are present in a hyperthyroid patient. The cardiovascular manifestations range from sinus tachycardia to atrial fibrillation and from a high cardiac output state to congestive heart failure (CHF) due to systolic left ventricular dysfunction. If the underlying hyperthyroidism is recognized and treated early, the CHF in such cases can be cured. This can be demonstrated in the case presented below.

\section{A Case Presentation}

A 51-year-old married woman was referred to Nigerian Air Force hospital Kaduna from a local hospital in Kebbi, Kebbi State, Nigeria because of persistent epigastric pain that lasted several weeks before her referral on 31 October, 2016. The pain was never relieved by any anti acids or proton pump inhibitors. In addition to the epigastric pain, she also complained of hand shaking, feeling excessive bodily heat, breathlessness on exertion, recurrent diarrhoea and loss of weight despite having a very good appetite. She denied palpitations, or near or total syncope. She also denied any history of cigarette, alcohol or drug abuse. The family history was negative for any significant disease.

On arrival, the patient was comfortable and in no acute distress. Her vital signs were: pulse 145 beats per minute, irregularly irregular, blood pressure $120 / 80 \mathrm{~mm} \mathrm{Hg}$, and respiratory rate $18 / \mathrm{min}$. She was febrile. Jugular venous pulsation was slightly elevated up to $3 \mathrm{~cm}$. The carotid upstroke was normal, and no carotid bruits were appreciated. A symmetrically enlarged, non tender thyroid gland was palpable, with a bruit over the left lobe. Mild stare and lid lag were noticed, along with mild tremor of the outstretched hands. Chest examination revealed no abnormalities. Heart examination revealed a non displaced apex beat, no right ventricular lift, and normal first and second heart sounds. The abdomen was mildly tender, and the liver palpable $2 \mathrm{~cm}$ below the costal margin. A slight pitting ankle oedema was noted bilaterally.

The results of laboratory investigations included: haemoglobin, $10.5 \mathrm{~g} / \mathrm{dL}$; hematocrit, $34 \%$; white cell count, $3.4 \mathrm{x}$ $10^{9} / \mathrm{L}$; platelets, $150 \times 10^{9} / \mathrm{L}$; blood urea nitrogen, $18.6 \mathrm{mg} / \mathrm{dL}$; and creatinine $1.4 \mathrm{mg} / \mathrm{dl}$. Electrolytes as well as cardiac enzymes were normal. Chest x-ray revealed mild cardiomegaly. ECG revealed atrial fibrillation with a left ventricular hypertrophy. An initial diagnosis of atrial fibrillation and congestive heart failure (CHF) secondary to thyrotoxicosis was made. A blood sample was taken for a thyroid function tests (TFT).

The patient was started on intravenous furosemide, oral digoxin and angiotensin-converting enzyme (ACE) inhibitors. Thyroid function tests ordered on admission revealed a thyroidstimulating hormone (TSH) level of $0.04 \mu \mathrm{U} / \mathrm{mL}$ (normal, $0.39-$ $6.16 \mu \mathrm{U} / \mathrm{mL}$ ) and a free thyroxine level of $\mathrm{T} 3=4.4$ (normal, $0.52-$ 
$1.85 \mathrm{ng} / \mathrm{ml}$ ). T4=10.4 (normal, $0.4 .8-11.6 \mu \mathrm{g} / \mathrm{ml}$ ), confirming the diagnosis of thyrotoxicosis. Over the next few days, the patient's condition improved, with complete resolution of hepatomegaly and fluid overload. She eventually was placed on carbimazole 20 mg daily and atenolol $100 \mathrm{mg}$ daily. Within the next 5 days her ECG spontaneously converted to sinus rhythm, and her TFTs markedly improved. However, three months after the commencement of the carbimazole, her TSH level was $13.6 \mathrm{mU} / \mathrm{L}$; T4 was $9.4 \mathrm{ug} / \mathrm{ml}$, while T3 was $0.9 \mathrm{ug} / \mathrm{ml}$. Following this result, the carbimazole was stopped and the patient was continued on the beta blocker Atenolol. Patient has remained stable since then.

\section{Discussion}

A case of severe but reversible systolic Left Ventricular dysfunction due to undetected hyperthyroidism has been presented. Failure to recognise the features of hyperthyroidism early enough as in the case of our patient, has probably led to the development of congested heart failure. Hyperthyroidism, can present with a wide variety of signs and symptoms. Typically, it presents with the features of heat intolerance, weight loss, sweating, palpitation, tremors, and diarrhoea. If left untreated, it can cause heart failure. Occasionally, it presents with heart failure in the absence of any classic symptoms of hyperthyroidism, as is the case with our patient who was thought to suffer from gastritis and esophagitis for several weeks before referral to our centre. Many of the effects of hyperthyroidism, such as tachycardia, tremors, and nervousness, resemble a state of adrenergic hyper function. These effects are thought to be mediated by an increase in the intracellular G protein and an increase in the number of $\beta$ receptors [1]. In addition; thyroid hormone can directly act on the sinus node [2]. Thyroid hormone exerts its cardiac effects indirectly through its effect on the vasculature and body metabolism, and directly through its effect on the heart. Peripherally, triiodothyronine (T3) has been shown to decrease systemic vascular resistance (SVR) by promoting vasodilatation [3]. This action is mediated by the direct effect of T3 on vascular smooth muscle [4]. The resulting decrease in SVR activates the renin-angiotensin-aldosterone system, leading to retention of sodium $(\mathrm{Na}+)$ and fluid [5]. Thyroid hormone also increases erythropoiesis. The net effect is a resultant increase in the total blood volume [6] and stroke volume. At the myocyte level, T3 enters the cell via specific transport proteins, [7] resulting in enhanced contractility and relaxation [8] of the myocardial cells through transcription- and non-transcription-mediated effects. The transcriptional effects lead to increased contractility through effects on the release and uptake of sarcoplasmic reticular calcium (Ca++) and phosphorylation of phospholamban $[9,10]$. The non-transcriptional effects are mediated by the effect of thyroid hormone on various ion channels [11]. These cardiac effects, coupled with a generalized increase in tissue metabolism, low SVR, an increase in total blood volume, lead to a high cardiac output state in hyperthyroidism.

Clinically, the effects of excess thyroid hormone on the cardiovascular system translate into a wide variety of signs and symptoms, ranging from sinus tachycardia to the development of severe left ventricular (LV) dysfunction and heart failure. Resting sinus tachycardia is the most common finding in hyperthyroidism, second only to goiter [12]. Thyrotoxicosis is an uncommon cause of atrial fibrillation, [13] which raises questions about the routine ordering of TSH levels in all patients with atrial fibrillation, but it is found in $5 \%-22 \%$ of hyperthyroid patients $[14,15]$ and is probably the most common cardiovascular problem that brings this disease to medical attention. In addition to overt thyrotoxicosis, the risk of atrial fibrillation is increased with subclinical hyperthyroidism [16]. The preferential involvement of the atria in hyperthyroidism is thought to be due to an abundance of $\beta$ receptors in the atria [17], the difference in the sensitivity of the atria and the ventricle to thyroid hormone, and the difference in autonomic input to the atria and the ventricles [18-20]. In hyperthyroidism, atrial fibrillation is often undertreated because it is usually resistant to digoxin; serum digoxin levels are low due to increased volume of distribution and metabolism [21, 22]. Therefore, higher than normal doses are required for adequate control of the ventricular rate. Uncontrolled atrial fibrillation of long duration has been linked to development of "tachycardiarelated cardiomyopathy" in hyperthyroidism [21]. In up to $60 \%$ of cases, sinus rhythm is spontaneously restored within weeks of attaining a euthyroid state [23].

In addition to therapy aimed at hyperthyroidism, the first line of treatment of CHF secondary to hyperthyroidism is a $\beta$ blocker, except in patients with marked hypotension, reversible airway disease, and marked bradycardia, especially with second- or third degree atrioventricular block. Beta blockers not only help ameliorate the non cardiac symptoms of the disease but also decrease the heart rate, by controlling, sinus tachycardia and/or decreasing the ventricular response to atrial fibrillation by action on the $\beta 1$ receptors, in addition to other unproven actions [24-26]. These cardiac effects of $\beta$ blockers also lead to improvement of $\mathrm{LV}$ function. Although non selective $\beta$ blockers, such as propranolol, are commonly used in hyperthyroidism due to the theoretical advantage of blocking the peripheral $\beta 2$ receptors and their $\beta 1$ receptor action on the heart, cardio selective $\beta$ blockers can also be used. Although propranolol decreases the free T3 concentration and increases the serum reverse $\mathrm{T} 3$ concentration to a great extent, as compared to non selective $\beta$ blockers, the clinical significance of this effect is not known[27,28]. Cardio selective $\beta$ blockers, such as metoprolol and esmolol, have been shown to be effective, as compared to non cardio selective $\beta$ blockers in controlling symptoms of thyrotoxicosis $[29,30]$.

The role of $\beta$ blockers that possess $\alpha$ receptor blocking capabilities is less clear. Theoretically, $\alpha$ receptor blockade should not confer any additional benefits in a disease state with a low SVR and increased heart rate. In some patients who cannot tolerate $\beta$ blockers, such as those with reversible airway disease, a non dihydropyridine calcium channel blocker, such as diltiazem, can be used. Diltiazem has been shown to be safe and effective in ameliorating the hyper adrenergic symptoms of hyperthyroidism, when compared with $\beta$ blockers [31, 32]. In addition to definitive therapy, oral or intravenous diuretics should be used for symptomatic relief. Whether ACE inhibitors should be started as a part of the initial treatment is not clear, 
as no clinical trial data are available. It is empirically believed that, an ACE inhibitor should be part of the initial drug regimen, especially if the ejection fraction (EF) is markedly depressed and if there is concern about any other etiologic factors. Digoxin is reasonable with a low $\mathrm{EF}$, fast ventricular rate in atrial fibrillation, and/or moderate to severe CHF. All cardiac medications can be gradually withdrawn once the euthyroid state has been achieved, the LVEF has improved, and sinus rhythm has returned, with periodic clinical or echo cardio graphic assessment of LV function. $\mathrm{LV}$ function tends to improve within a few weeks of initiation of treatment of thyrotoxicosis and heart failure. In particular, LV function improves when the rapid ventricular rate, due to either sinus tachycardia or atrial fibrillation, is brought under control.

\section{Conclusion}

We conclude that hyperthyroidism can cause severe, but readily reversible, $\mathrm{LV}$ dysfunction in relatively young individuals. We also showed that this disease can be diagnosed by a detailed history and physical examination, which is a declining clinical skill, and that the TSH level should be checked as a part of the initial laboratory work-up of every patient with new-onset CHF.

\section{References}

1. Levey GS, Klein I. Catecholamine thyroid hormone interactions and the cardiovascular manifestation of hyperthyroidism. Am J Med. 1990;88:642-646.

2. Valcavi R, Menozzi C, Roti E, Zini M, Lolli G, Roti S, et al. Sinus node function in hyperthyroid patients. J Clin Endocrinol Metab. 1992;75(1):239-242.

3. Park KW, Dai HB, Ojamaa K, Lowenstein E, Klein I, Sellke FW. The direct vasomotor effect of thyroid hormone on rat skeletal muscle resistance arteries. Anesth Analg. 1997;85(4):734-738.

4. Ojamaa K, Klemperer JD, Klein I. Acute effects of thyroid hormone on vascular smooth muscle. Thyroid. 1996;6(5):505-512.

5. Resnick LM, Laragh JH. Plasma renin activity in syndromes of thyroid hormone excess and deficiency. Life Sci. 1982;30(7-8):585-586.

6. Gibson JG, Harris AW. Clinical studies of the blood, volume V. Hyperthyroidism and myxedema. J Clin Invest. 1939;18(1):59-65.

7. Everts ME, Verhoeven FA, Bezstarosti K, Moerings EP, Hennemann G, Visser TJ, et al. Uptake of thyroid hormones in neonatal rat cardiac myocytes. Endocrinology. 1996;137(10):4235-4242.

8. Mintz G, Pizzarello R, Klein I. Enhanced left ventricular diastolic function in hyperthyroidism: non-invasive assessment and response to treatment. J Clin Endocrinol Metab. 1991;73(1):146-150.

9. Kiss E, Jakab G, Kranias EG, I Edes. Thyroid hormone induced alteration in phospholamban protein expression: regulatory effects on sarcoplasmic reticulum Ca2+ transport and myocardial relaxation. Circ Res. 1994;75:245-251. doi.org/10.1161/01.RES.75.2.245

10. Ojamaa K, Kennesey A, Klein I. Thyroid hormone regulation of phospholamban phosphorylation in the rat heart. Endocrinology. 2000;141(6):2139-2144. doi.org/10.1210/endo.141.6.7514
11. Davis PJ, Davis FB. Acute cellular actions of thyroid hormone and myocardial function. Ann Thorac Surg. 1993;56(1):S16-S23. doi. org/10.1016/0003-4975(93)90550-2

12. Nordyke RA, Gilbert FI Jr, Harada ASM. Graves' disease: influence of age on clinical findings. Arch Intern Med. 1988;148(3):626-631. doi:10.1001/archinte.1988.00380030132023

13. Krahn AD, Klen GR, Kerr CR, Boone J, Sheldon R, Green M,et al. How useful is thyroid function testing in patients with recent-onset atrial fibrillation? Arch Intern Med. 1996;156(19):2221-2224.

14. Klein I, Ojamaa K. Thyrotoxicosis and the heart. Endocrinol Metab Clin North Am. 1998;27:51-62. /dx.doi.org/10.1016/S08898529(05)70297-8

15. Woeber KA. Thyrotoxicosis and the heart. N Engl J Med. 1992;327:94-98. DOI: 10.1056/NEJM199207093270206

16. Sawin CT, Geller A, Wolf PA, et al. Low serum thyrotropin concentrations as a risk factor for atrial fibrillation in older persons. N Engl J Med. 1994;331:1249-1252. DOI: 10.1056/NEJM199411103311901

17. Golf S, Lovstad R, Hansson V. Beta-adrenoceptor density and relative number of beta-adrenoceptor subtypes in biopsies from human right atrial, left ventricular, and right ventricular myocardium. Cardiovasc Res. 1985;19(10):636-641.

18. Polikar R, Burger AG, Scherrer U, Nicod P. The thyroid and the heart. Circulation. 1993;87(5):1435-1441.

19. Martin WH III, Spina RJ, Korte E, EllenKorte MA. Effect of hyperthyroidism of,short duration on cardiac sensitivity to betaadrenergic stimulation. J Am Coll Cardiol. 1992;19(6):1185-1191. doi. org/10.1016/0735-1097(92)90322-E

20. Maciel BC, Gallo L Jr, Marin Neto J, Maciel LM, Alves ML, Paccola GM, et al. The role of the autonomic nervous system in the resting tachycardia of human hyperthyroidism. Clin Sci. 1987;72(2):239-244.

21. Juhl-Johnsen C, Kokenge F, Kolenda KD. Serum level of digoxin and digitoxin and glomerular filtration rate in hyper- and hypothyroidism [in German]. Dtsch Med Wochensch. 1983;108(10):378-383. DOI:10.1055/s-2008-1069562

22. Gaita F, Bocchiardo M, Brossa C, Brusca A. Serum levels and kinetics of digoxin in patients with hyperthyroidism [in Italian]. G Ital Cardiol. 1980;10(7):836-842.

23. Nakazawa HK, Sakurai A, Hamada N, Momotani N, Ito K.. Management of atrial fibrillation in the post thyrotoxic state. Am J Med. 1982;72(6):903-906.

24. Gilligan DM, Ellenbogen KA, Epstein AE. The management of atrial fibrillation. Am J Med. 1996:101(4):413-421.

25. Peterson P, Hansen JM. Stroke in thyrotoxicosis with atrial fibrillation. Stroke. 1988;19(1):15-18.

26. Olshausen KV, Bischoff S, Kahaly G, Mohr-Kahaly S, Erbel R, Beyer J, et al. Cardiac arrhythmias and heart rate in hyperthyroidism. Am J Cardiol. 1989;63(13):930-933.

27. Toft P, Botker HE. Hyperthyroidism and heart disease. Is thyrotoxic cardiomyopathy a disease entity [in Danish]? Ugeskr Laeger. 1993;155(18):1354-1357. 
28. Cavallo A, Casta A, Fawcett HD, Nusynowitz ML, Wolf WJ.. Is there a thyrotoxic cardiomyopathy in children? J Pediatr. 1985;107:531-536.

29. Pereira N, Parisi A, Dec GW, Choo J, Hajjar R, Gordon PC. Myocardial stunning in hyperthyroidism. Clin Cardiol. 2000;23(4):298-300.

30. Marti V, Ballester M, Obrador D, MOYA C, CARRIO I, PONS-LLADÓ G. Active myocardial damage in hyperthyroidism. A concurrent mechanism of heart failure reversed by treatment. Eur Heart J. 1995;16(7):1014-1016.

31. Martinez Velasco MC, Lobo Palanco J, Anguiano Baquero P, Beunza Puyal MT. Acute myocardial infarction and thyrotoxicosis. A report of a new case. Rev Esp Cardiol. 1999;52(11):1019-1021.

32. Locker GJ, Kotzmann H, Frey B, Messina FC, Sterz FR, Weissel M, et al. Factitious hyperthyroidism causing acute myocardial infarction. Thyroid. 1995;5:465-467.

33. Bergeron GA, Goldsmith R, Schiller NB. Myocardial infarction, severe reversible ischemia, and shock following excess thyroid administration in a woman with normal coronary arteries. Arch Intern Med. 1988;148(6):1450-1453.

34. Proskey AJ, Saksena F, Towne WD. Myocardial infarction associated with thyrotoxicosis. Chest. 1977;72(1):109-111.

35. Peters A, Ehlers M, Blank B, Exler D, Falk C, Kohlmann T, et al. Excess triiodothyronine as a risk factor for coronary events. Arch Intern Med. 2000;160(19):1993-1999.

36. Rajasoorya C. Examining the therapeutic options in hyperthyroidism - a personal perspective. Ann Acad Med Singapore. 1993;22(4):617-623.

37. Geffner DL, Hershman JM. Beta-adrenergic blockade for the treatment of hyperthyroidism. Am J Med. 1992;93:61-68.
38. Feely J, Peden N. Use of beta-adrenoceptor blocking drugs in hyperthyroidism. Drugs. 1984;27(5):425-446.

39. Murchison LE, How J, Bewshwr PD. Comparison of propranolol and metoprolol in the management of hyperthyroidism. Br J Clin Pharmacol. 1979;8(6):581-587.

40. Wiersinga WM. Propranolol and thyroid hormone metabolism. Thyroid. 1991;1(3):273-277. DOI: 10.1089/thy.1991.1.273

41. Vickers P, Garg KM, Arya R, Godha U, Mathur P, Jain S. The role of selective beta-1 blocker in the preoperative preparation of thyrotoxicosis: a comparative study with propranalol. Int Surg. 1990;75(3):179-183.

42. Isley WL, Dahl S, Gibbs H. Use of esmolol in managing a thyrotoxic patient needing emergency surgery. Am J Med. 1990;89(1):122-123.

43. Roti E, Montermini M, Roti S, Gardini E, Robuschi G, Minelli R, et al. The effect of diltiazem, a calcium channel blocking drug, on cardiac rate and rhythm in hyperthyroid patients. Arch Intern Med. 1988;148(9):919921.

44. Milner MR, Gelman KM, Phillips RA, Fuster V, Davies TF, Goldman ME. Double-blind crossover trial of diltiazem versus propranalol in the management of thyrotoxic symptoms. Pharmacotherapy. 1990;10(2):100-106.

45. McCullough PA, Cingireddy U, Philbin EF, WD Weaver. Evidence for a heart failure epidemic: findings from the REACH study. J Am Coll Cardiol. 1999;33:179A.

46. McCullough PA, Philbin EF, Czerska B, et al. The diagnostic evaluation of newly discovered heart failure: opportunities for improvement from the REACH Study. J Am Coll Cardiol. 2000;35:327A. 